\title{
Comparison of Autonomic Reactivity to the Stress between Adjustment Disorder and Major Depressive Disorder
}

\author{
Dae Jong $\mathrm{Oh}^{1,2}$, Sae Rom $\mathrm{Kim}^{3}$, Eun Young $\mathrm{Kim}^{4,5}$, and Myung Jae Baik ${ }^{6 凶}$ \\ ${ }^{1}$ Department of Psychiatry, Seoul National University College of Medicine, Seoul, Republic of Korea \\ ${ }^{2}$ Department of Psychiatry, SMG-SNU Boramae Medical Center, Seoul, Republic of Korea \\ ${ }^{3}$ Department of Psychiatry, Armed Forces Capital Hospital, Seongnam, Republic of Korea \\ ${ }^{4}$ Mental Health Center, Seoul National University Health Care Center, Seoul, Republic of Korea \\ ${ }^{5}$ Department of Human Systems Medicine, Seoul National University College of Medicine, Seoul, Republic of Korea \\ ${ }^{6}$ Gyeonggi Provincial Mental Health Center, Suwon, Republic of Korea
}

Objective Adjustment disorder (AD) remains an ambiguous diagnosis that overlaps with major depressive disorder (MDD). This study compared autonomic reactivity to the stress between $\mathrm{AD}$ and $\mathrm{MDD}$ to test for biological differences.

Methods Physically healthy Korean male soldiers admitted to a psychiatric ward were recruited for participation. Clinical diagnoses indicated that 62 patients with $\mathrm{AD}$ and 47 with MDD were selected. Procedures consisted of electrocardiogram measurements according to three consecutive phases lasting five minutes each [i.e., resting, stress (including a mental arithmetic task and Stroop color word test), and recovery].

Results The reactive trends of all heart rate variability (HRV) parameters related to the stress tasks in participants with AD did not differ from those with MDD. High-frequency HRV (a proxy of parasympathetic activity) increased during times of stress for participants with $\mathrm{AD}$ and MDD. Despite similar reactive trends, AD participants had higher HRV values than participants with MDD during whole phases, particularly for variables reflecting overall autonomic activity.

Conclusion $\mathrm{AD}$ is associated with higher basal activity in the autonomous nervous system when compared to MDD. However, both are associated with pathophysiology indicating an altered autonomic reactivity to stress.

Psychiatry Investig 2020;17(12):1175-1181

Key Words Adjustment disorder, Major depressive disorder, Heart rate variability, Autonomous nervous system, Stress reaction.

\section{INTRODUCTION}

Adjustment disorder (AD) is one of the most common psychiatric illnesses ${ }^{1-4}$ and a significant risk factor for suicidal behaviors. ${ }^{5-8}$ In particular, the prevalence rate of $\mathrm{AD}$ is approximately six times higher in Korean military population than in general population., ${ }^{9}$ Despite its high prevalence and serious impact, research on $\mathrm{AD}$ is profoundly underdeveloped due to

Received: June 1, 2020 Revised: July 12, 2020

Accepted: September 11, 2020

$\triangle$ Correspondence: Eun Young Kim, MD, PhD

Department of Human Systems Medicine, Seoul National University College of Medicine, 103 Daehak-ro, Jongno-gu, Seoul 03080, Republic of Korea

Tel: +82-2-880-8589, Fax: +82-2-880-9274, E-mail: ey00@snu.ac.kr

$\triangle$ Correspondence: Myung Jae Baik, MD

Gyeonggi Provincial Mental Health Center, 69 Suseong-ro 245beon-gil, Jangan-gu, Suwon 16316, Republic of Korea

Tel: +82-31-888-0750, Fax: +82-31-212-0442

E-mail: kinotopia100@hanmail.net

(c) This is an Open Access article distributed under the terms of the Creative Commons Attribution Non-Commercial License (https://creativecommons.org/licenses/bync/4.0) which permits unrestricted non-commercial use, distribution, and reproduction in any medium, provided the original work is properly cited. diagnostic ambiguity. It remains an unstable and subthreshold diagnosis rather than a discrete diagnostic entity. For instance, $\mathrm{AD}$ is frequently overlapped with other psychiatric illnesses, particularly major depressive disorder (MDD). ${ }^{11}$ However, longitudinal courses and therapeutic approaches indicate clear differences between $\mathrm{AD}$ and $\mathrm{MDD}$. In contrast to $\mathrm{MDD}, \mathrm{AD}$ is associated with a self-limiting course, short duration of illness, and low relapse rate. ${ }^{12-16}$ Thus, early differential diagnoses are needed for direct service planning and enhancing therapeutic efficacy to ensure the proper management of both conditions.

The biological underpinnings of $\mathrm{AD}$ and MDD should be understood because differential diagnosis efforts based on symptomatology have reached their limitations. ${ }^{17-19}$ However, the research in this area is strikingly scarce. Only two studies have tried to compare the Hypothalamic-Pituitary-Adrenal (HPA) axis dysfunction between $\mathrm{AD}$ and $\mathrm{MDD},{ }^{20,21}$ but no significant differences were found. Instead of conducting an assessment using the HPA axis, this study focused on dysfunction of the autonomous nervous system, which is another core 
pathophysiology of the human stress response. ${ }^{22}$ We previously compared heart rate variability $(\mathrm{HRV})^{23}$ (a reliable biomarker of autonomic activity as assessed through a non-invasive measurement ${ }^{24}$ ) between $\mathrm{AD}$ patients and healthy controls. We found that $\mathrm{AD}$ patients showed reversed autonomic reactivity to the dynamic stress tasks when compared to the normal stress reaction. However, no other studies have compared the autonomic reactivity of $\mathrm{AD}$ to that of MDD.

This study compared autonomic reactivity between $\mathrm{AD}$ and MDD patients by measuring dynamic changes in HRV during stress tasks. Because $\mathrm{AD}$ is associated with a better prognosis, we hypothesized that the reactive patterns of HRV to stress would be less altered in $\mathrm{AD}$ patients compared to those in $\mathrm{MDD}$ patients.

\section{METHODS}

\section{Participants}

We recruited male military soldiers aged 18 to 35 who had been admitted to the psychiatric ward of the Armed Forces Capital Hospital in Seongnam, Korea. Participants diagnosed with either $\mathrm{AD}$ or MDD were selected for analysis in this study from August 2016 to August 2018. Experienced psychiatrists clinically diagnosed $\mathrm{AD}$ and $\mathrm{MDD}$ in participants according to the Diagnostic and Statistical Manual of Mental disorders, 5th edition (DSM-5). Participants with comorbid physical illnesses (e.g., cardiovascular diseases, hypertension, diabetes mellitus, asthma, acute respiratory infection, thyroid diseases, and/or drug intoxication) or those taking medication (e.g., sympathomimetics, anticholinergics, vasodilators, and/or anti-hypertensives) that could strongly affect the autonomic nervous system were excluded from analysis. We also excluded users of tricyclic antidepressants because of their remarkable anticholinergic and a1-adrenergic properties. ${ }^{25}$ The study protocol was approved by the Institutional Review Board of the Armed Forces Medical Command(AFMC-12-IRB-010).

\section{Stress task and HRV measurement}

Stress tasks and related HRV measurements were performed at the time of admission by a trained medical laboratory technologist who was blinded to all clinical diagnoses. All procedures were performed in a quiet, air-conditioned room set to an ambient temperature of $22-25^{\circ} \mathrm{C}$. To analyze beat-to-beat $\mathrm{HRV}$, an electrocardiogram was conducted by placing a photoplethysmography sensor on the third finger of the right hand. HRV parameters were measured using the ProComp2 system and Biograph Infiniti Software (Thought Technology Ltd., Quebec, Canada). All participants were prohibited from drinking coffee, smoking, exercising, or taking any medications within a 12-hour period before the testing procedure. They were seated in a comfortable armchair and informed to relax while breathing slowly and naturally. The procedure began after a five-minute rest period. The assessment took a total of 15 minutes and consisted of the three following consecutive phases (five minutes each): Resting phase, stress phase, and recovery phase. Participants were informed to relax and stare at green spots on a nearby screen during the resting and recovery phases. Stressphase tasks consisted of a mental arithmetic task and Stroop color word test half-and-half. The mental arithmetic task consisted of a serial subtraction in increments of seven beginning with the number 1,081, while the Stroop color word test entailed that participants state the actual observed colors of written words denoting different colors (i.e., the written color did not match the displayed color). All participants were prompted to answer as fast as they could during these stress tasks.

\section{HRV parameters}

A power spectrum analysis was conducted using a nonparametric fast Fourier transformation. The distribution of spectral power was transformed into the function of frequency and then quantified into standard frequency-domain parameters. ${ }^{26}$ The frequency-domain parameters included high frequency HRV (HF, 0.15-0.40 Hz), low frequency HRV (LF, 0.04-0.15 $\mathrm{Hz}$ ), very low frequency HRV (VLF, $0.003-0.04 \mathrm{~Hz}$ ), total power (TP), and the ratio of LF to HF HRV (LF/HF). As a time-domain parameter, the standard deviation of normal-to-normal interbeat interval (SDNN) was also measured.

\section{Assessing symptom severity}

All participants completed the Korean versions of the Center for Epidemiologic Studies Depression scale (CES-D) for depressive symptoms, ${ }^{27}$ Beck Anxiety Inventory (BAI) for anxiety symptoms, ${ }^{28}$ Perceived Stress Scale (PSS) for stress responses, ${ }^{29}$ and Scale for Suicide Ideation (SSI) for suicidality. ${ }^{30}$

\section{Statistical analysis}

We compared sociodemographic and clinical characteristics between groups using Pearson's chi-square tests for categorical variables and Student's t-tests for continuous variables. All HRV parameters (e.g., the band powers of HF, LF, VLF, TP, and $\mathrm{LF} / \mathrm{HF}$ and the SDNN) were logarithmically transformed to correct for skewed distributions. Repeated measures analyses of variance (ANOVA) were performed to analyze intergroup differences regarding changes in HRV parameters throughout the assessment, with adjustment of $\mathrm{p}$ values by using Bonferroni's method (adjusted $\mathrm{p}=0.05 / 3$ ). Meanwhile, intergroup differences in HRV parameters were analyzed using Student's ttests during each of the three phases. Finally, we performed sensitivity analyses by calculation of the Pearson's correlation coefficients between HRV parameters and symptom severity. 
All statistical analyses were performed using the SPSS 19.0 (IBM Corp., Armonk, NY, USA) statistical package.

\section{RESULTS}

\section{Sociodemographic and clinical characteristics}

Analyses were conducted on data from 62 patients with $\mathrm{AD}$ and 47 patients with MDD. All participants were male (mean age of $21.5 \pm 2.8$ years). There was no missing data in all HRV parameters of both groups.

Table 1 shows participant sociodemographic and clinical characteristics. The $\mathrm{AD}$ group did not differ from MDD group regarding the possible confounders affecting HRV parameters (e.g., age, smoking, body mass index, blood pressure, and significant antidepressant use as defined by a dosage taken for more than four weeks). The mean duration of antidepressant usage was also comparable between groups ( $\mathrm{AD} 5.5 \pm 7.6$ weeks, MDD 6.0 \pm 9.8 weeks, $\mathrm{p}=0.823$ ). Histories of mental illnesses, suicide attempts, and symptom severity related to depression, anxiety, stress response, and suicidality were also highly similar between groups (Table 1). The proportion of military personnel who was conscripted was higher in $\mathrm{AD}$ group than that of MDD group (93.5\% vs. $78.7 \%, \mathrm{p}=0.022$ ).

\section{Autonomic reactivity to mental stress}

The repeated-measures ANOVAs revealed similar trends in reactive changes in HRV over whole phases between the $\mathrm{AD}$ and MDD groups (Figure 1). The interaction effect of group *time was not statistically significant for any HRV parameters (HF, F=0.734, $\mathrm{p}=0.481, \eta_{\mathrm{p}}^{2}=0.007 ; \mathrm{LF}, \mathrm{F}=0.334, \mathrm{p}=0.705, \eta_{\mathrm{p}}^{2}=$
0.003; VLF, $\mathrm{F}=0.785, \mathrm{p}=0.457, \eta_{\mathrm{p}}^{2}=0.007 ; \mathrm{TP}, \mathrm{F}=0.458, \mathrm{p}=0.633$, $\eta_{\mathrm{p}}^{2}=0.004 ; \mathrm{LF} / \mathrm{HF}, \mathrm{F}=0.672, \mathrm{p}=0.512, \eta_{\mathrm{p}}^{2}=0.006 ; \mathrm{SDNN}, \mathrm{F}=$ $\left.0.656, \mathrm{p}=0.520, \eta_{\mathrm{p}}^{2}=0.006\right)$.

Although we found no intergroup differences in reactivity trends, Student's t-tests revealed significant intergroup differences in the values of several HRV parameters (Figure 1, Supplementary Table 1 in the online-only Data Supplement). Dur-

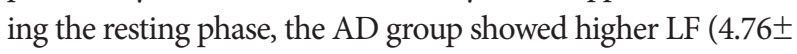
$0.96 \mathrm{~ms}^{2}$ vs. $\left.4.27 \pm 1.12 \mathrm{~ms}^{2}, \mathrm{p}=0.016\right), \operatorname{VLF}\left(4.47 \pm 0.85 \mathrm{~ms}^{2}\right.$ vs. $\left.3.97 \pm 0.93 \mathrm{~ms}^{2}, \mathrm{p}=0.004\right)$, TP $\left(5.68 \pm 0.91 \mathrm{~ms}^{2}\right.$ vs. $5.22 \pm 1.07$ $\left.\mathrm{ms}^{2}, \mathrm{p}=0.016\right)$, and SDNN (3.90 $\pm 0.45 \mathrm{~ms}$ vs. $3.69 \pm 0.57 \mathrm{~ms}$, $\mathrm{p}=0.038$ ) when compared to MDD group. During the stress phase, the $\mathrm{AD}$ group only showed higher values for $\mathrm{LF}$ (5.13 \pm $0.87 \mathrm{~ms}^{2}$ vs. $\left.4.76 \pm 0.78 \mathrm{~ms}^{2}, \mathrm{p}=0.022\right)$ and TP $\left(5.86 \pm 0.85 \mathrm{~ms}^{2}\right.$ vs. $\left.5.51 \pm 0.77 \mathrm{~ms}^{2}, \mathrm{p}=0.030\right)$. Finally, $\mathrm{LF}\left(4.97 \pm 0.89 \mathrm{~ms}^{2}\right.$ vs. $\left.4.52 \pm 1.13 \mathrm{~ms}^{2}, \mathrm{p}=0.020\right)$, TP $\left(5.87 \pm 0.92 \mathrm{~ms}^{2}\right.$ vs. $5.42 \pm 1.07$ $\left.\mathrm{ms}^{2}, \mathrm{p}=0.021\right)$, and SDNN $\left(4.00 \pm 0.47 \mathrm{~ms}^{2}\right.$ vs. $3.78 \pm 0.52 \mathrm{~ms}^{2}$, $\mathrm{p}=0.021$ ) were higher among the AD group than the MDD group during the recovery phase.

In correlation analyses, the changes of HRV parameters were correlated with symptom severity in $\mathrm{AD}$ whereas those correlations were less obvious in MDD. During the stress phase in $\mathrm{AD}$ group, the increase of $\mathrm{HF}$ had positive correlation with the scores of CES-D ( $r=0.468, p<0.001)$, PSS $(r=0.413, p=0.001)$, and BAI $(r=0.459, p<0.001)$, whereas the decreases of LF and $\mathrm{LF} / \mathrm{HF}$ had correlation with increasing scores of BAI ( $r=-0.275$, $\mathrm{p}=0.032)$ and PSS $(\mathrm{r}=-0.258, \mathrm{p}=0.047)$ respectively. During the stress phase in MDD group, the decrease of SDNN had correlation with increasing scores of BAI ( $r=-0.291, \mathrm{p}=0.047)$.

Table 1. Sociodemographic and clinical characteristics of participants

\begin{tabular}{lccc}
\hline & Adjustment disorder $(\mathrm{N}=62)$ & Major depressive disorder $(\mathrm{N}=47)$ & Statistics* p-value $^{-}$ \\
\hline Age, mean (SD), years & $20.98(2.18)$ & $22.06(3.46)$ & 0.065 \\
Education, <10 years, No. (\%) & $17(27.9)$ & $16(34.8)$ & 0.443 \\
Current smoking, No. (\%) & $20(32.3)$ & $17(36.2)$ & 0.669 \\
BMI, mean (SD), kg/m & $23.43(2.78)$ & $24.30(4.03)$ & 0.189 \\
SBP, mean (SD), mm Hg & $120.05(11.06)$ & $120.48(13.49)$ & 0.857 \\
DBP, mean (SD), mm Hg & $69.74(9.43)$ & $68.54(9.83)$ & 0.526 \\
Antidepressants use, No. (\%) ${ }^{\dagger}$ & $22(35.5)$ & $13(27.7)$ & 0.386 \\
History mental illness, No. (\%) & $10(16.1)$ & $22(48.9)$ & 0.860 \\
History of suicide attempt, No. (\%) & $23(37.1)$ & $39.45(15.43)$ & 0.223 \\
CES-D score, mean (SD) & $37.69(15.31)$ & $25.89(16.68)$ & 0.557 \\
BAI score, mean (SD) & $27.38(15.72)$ & $28.47(7.40)$ & 0.637 \\
PSS score, mean (SD) & $29.13(6.94)$ & $18.49(9.08)$ & 0.634 \\
SSI score, mean (SD) & $18.71(9.01)$ & 0.900 \\
\hline
\end{tabular}

*student's t-test for continuous variables; Pearson's chi-squared test for categorical variables, ${ }^{\dagger}$ any dosage of antidepressants use more than 4 weeks. BMI: body mass index, SBP: systolic blood pressure, DBP: diastolic blood pressure, CES-D: Center for Epidemiologic Studies Depression scale, BAI: Beck Anxiety Inventory, PSS: Perceived Stress Scale, SSI: Scale for Suicide Ideation 


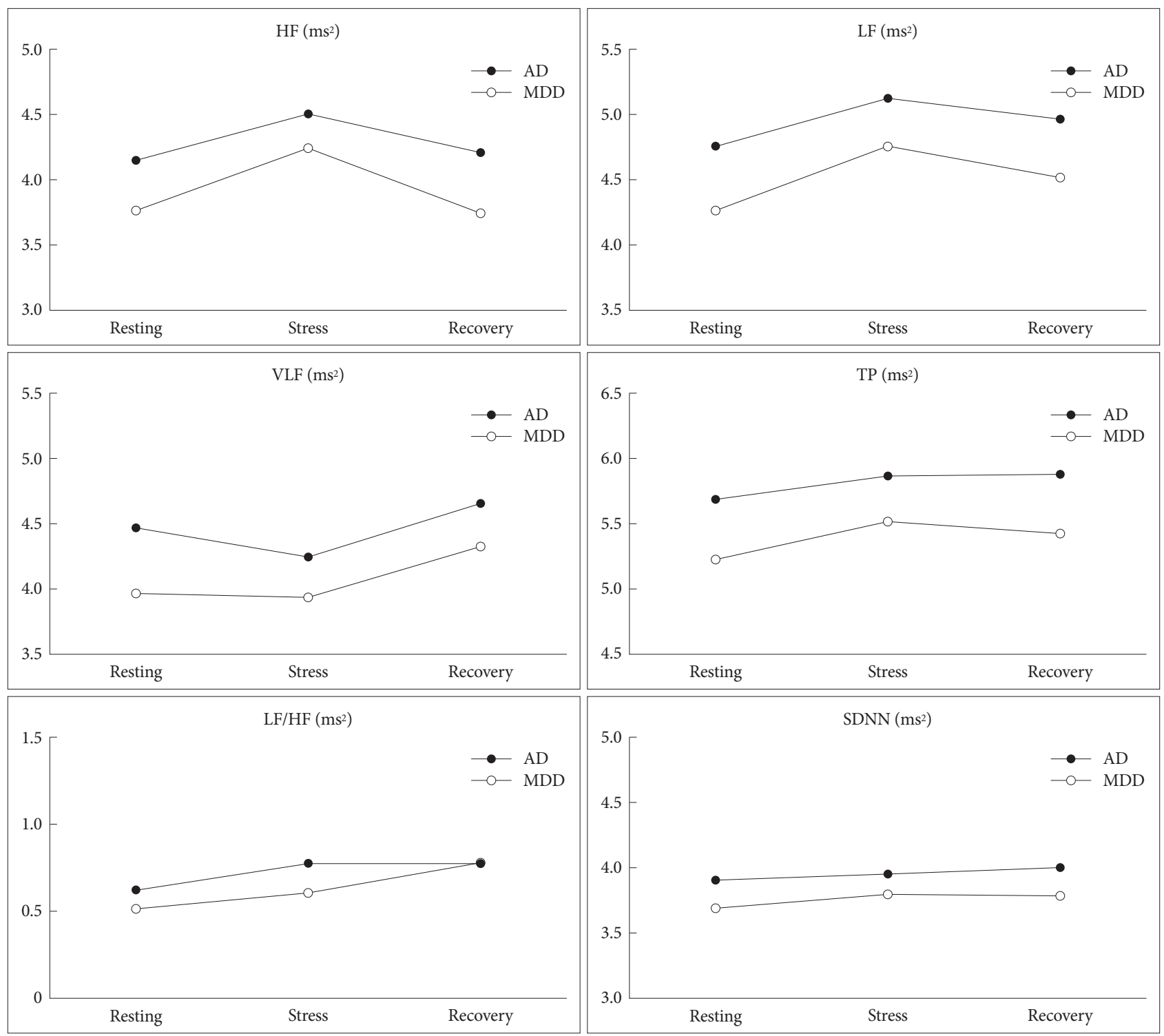

Figure 1. Comparison of reactive heart rate variability between adjustment disorder and major depressive disorder. All variables were logarithmically transformed due to their skewed distribution. AD: adjustment disorder, MDD: major depressive disorder, HF: high frequency band $\left(\mathrm{ms}^{2}\right)$, LF: low frequency band $\left(\mathrm{ms}^{2}\right)$, VLF: very low frequency band $\left(\mathrm{ms}^{2}\right)$, TP: total power $\left(\mathrm{ms}^{2}\right)$, LF/HF: ratio of LF to HF power, SDNN: standard deviation of normal-to-normal interbeat intervals (ms).

\section{DISCUSSION}

This study found no differences in the reactive trends among any HRV parameters during mental stress tasks between participants with $\mathrm{AD}$ and MDD. These results did not support our initial hypothesis. Rather, there were differences between the $\mathrm{AD}$ and MDD groups in HRV values such as SDNN, TP, LF, and VLF throughout whole phases. Increased focus should thus be placed on the quantitative aspects of autonomic activity rather than its reactive pattern to stresses when attempting to biologically distinguish AD from MDD.

MDD patients have consistently exhibited altered HRV reactivity during stress. This is especially true for HF (a proxy of parasympathetic activity ${ }^{31}$ ), which has thoroughly been replicated as a strong hallmark of MDD. In contrast to the normal stress reaction accompanied by sympathetic activation and parasympathetic withdrawal, ${ }^{32} \mathrm{HF}$ further decreased or reversely increased in MDD patients during stress. ${ }^{33} \mathrm{AD}$ patients also showed smaller reactivity for HF during stress tasks than the healthy control group in our previous study. ${ }^{23}$ This study was the first to compare autonomic reactivity between patients with $\mathrm{AD}$ and MDD. We replicated the increasing trends of $\mathrm{HF}$ during stress in $\mathrm{AD}$ patients as much as in those with MDD. We therefore speculate that $\mathrm{AD}$ shares a common pathophysiology with MDD as presented through an impaired parasympathetic withdrawal to the applied stress. Based on the signifi- 
cant correlation between HF changes and symptom severity in $\mathrm{AD}$ group of this study, we may suggest that the impaired parasympathetic withdrawal is one of the core biological marker of AD. However, as this study has a key limitation of lacking a direct comparison with healthy controls, we should be cautious to conclude that normal parasympathetic withdrawal was impaired in $\mathrm{AD}$ and MDD. Further studies including the data from healthy controls should follow to clearly understand the patterns of autonomic reactivity in both conditions.

Consistent with the results of HF, LF increased during stress tasks among patients with $\mathrm{AD}$ and MDD. Previous reports from healthy controls showed conflicting results for LF; some reported increasing $\mathrm{LF}^{34,35}$ while others reported decreasing LF during stress tasks. ${ }^{36,37}$ Reports from tests among MDD patients also revealed mixed results for the reactive change of LF to the applied stress. ${ }^{33}$ Contrary to cases involving HF, there is thus a clear limitation to interpreting the reactive trends of LF revealed in this study. Notably, these results instead clarify the larger values of $\mathrm{LF}$ in $\mathrm{AD}$ patients more so than those in MDD patients during whole phases. LF could reflect both sympathetic and parasympathetic activity for short-term measurements such as those taken during this study. ${ }^{38,39}$ Despite similar reactive patterns, patients with $\mathrm{AD}$ may therefore have greater overall autonomic activity compared to those with MDD.

$\mathrm{AD}$ patients had larger values of SDNN and TP than MDD patients during nearly all phases. Like LF, SDNN and TP have also been known to represent overall autonomic activity. ${ }^{40}$ This evidence supports the idea of a more enhanced basal activity for the whole autonomic nervous system in $\mathrm{AD}$ patients when compared to those with MDD. Meanwhile, the reactive trends of SDNN and TP did not differ between AD and MDD patients; those variables increased during stress among participants with both conditions. Although the reactive change of TP to the stress was not well known, SDNN exhibited decreasing trends during stress tasks for normal stress reactions. ${ }^{32,37}$ Liang et al. ${ }^{41}$ reported decreasing SDNN and TP during mental arithmetic tasks in patients with MDD, which is contrary to this study's findings. This discrepancy may be a result of differences in age, body mass index, antidepressant usage, and depressive episode histories between study participants.

We found decreasing trends for VLF during stress in both the AD and MDD groups. This was consistent with our previous report, which revealed decreasing VLF in $\mathrm{AD}$ patients and oppositely increasing VLF in healthy controls during stress tasks. ${ }^{23}$ The VLF component mainly reflects sympathetic activity. ${ }^{39}$ Thus, the impaired sympathetic dominance during stress may underlie both AD and MDD. Additionally, a larger resting VLF among AD patients when compared to MDD patients in this study may mean that $\mathrm{AD}$ patients have more enhanced basal sympathetic activity. However, our VLF results should be cautiously interpreted; the LF/HF ratio, which represents sympatho-vagal balance, ${ }^{39}$ was similar for both conditions. Furthermore, the relatively reduced VLF in MDD patients may reflect another pathophysiology rather than autonomic activity (e.g., inflammation) because VLF had a negative correlation with pro-inflammatory markers. ${ }^{42,43}$

This study had several limitations. First, we could not exclude the influence of antidepressants; many participants had already been prescribed in an outpatient setting before admission. However, a meta-analysis revealed that antidepressants other than tricyclic agents had no significant effects on HRV measurement results. ${ }^{44}$ Although other studies have reported opposite results, ${ }^{45,46}$ their focus was on long-term usage (e.g., about two years). This study excluded participants who were using tricyclic antidepressants. Furthermore, the mean duration of antidepressant usage was as short as six weeks. In addition, the impact of antidepressants on our findings did not seem significant because the mean duration of antidepressant usage and instances of significant antidepressant usage above four weeks were all comparable between the AD and MDD groups. Second, the neutral stress tasks used in this study could not directly reflect the nature of real-world stressors for $\mathrm{AD}$ patients. Third, there is a limitation of generalizing the results as the participants were composed of military soldiers only. Fourth, there was no information on the duration of disease which could lead to the substantial impact on HRV parameters. Finally, almost all HRV parameters used in this study were restricted to frequency-domain analyses due to our short-term measurement periods of five minutes. Further investigation is needed to determine whether autonomic reactivity varies according to the type of stressor and the duration of measurement.

Despite these limitations, this study was the first to compare the biological underpinnings of $\mathrm{AD}$ with those of $\mathrm{MDD}$. There were no differences in reactive HRV trends regarding stress between the AD and MDD groups, which also had similar sociodemographic and clinical variables (including symptom severity). However, higher HRV values indicated higher basal activity in the autonomic nervous system for patients with $\mathrm{AD}$ compared to those with MDD. HRV may indicate the "allostatic capacity" for achieving adaptation through cardiac autonomic regulation during stress. ${ }^{47}$ We thus suggest that $\mathrm{AD}$ patients may have a much better capacity for adapting to stressful conditions. This could partially explain the better prognoses and self-limiting disease courses of $\mathrm{AD}$ patients when compared to those among MDD patients, whose cardiac autonomic regulation is much more seriously dampened and inflexible.

\section{Supplementary Materials}

The online-only Data Supplement is available with this article at https://doi.org/10.30773/pi.2020.0209. 


\section{Acknowledgments}

This work was supported by a grant from the Armed Forces Medical Research Institute (Grant No. AFMC-12-012).

\section{Conflicts of Interest}

The authors have no potential conflicts of interest to disclose.

\section{Author Contributions}

Conceptualization: Dae Jong Oh, Eun Young Kim, Myung Jae Baik. Data curation: Dae Jong Oh, Sae Rom Kim, Myung Jae Baik. Formal analysis: Dae Jong Oh. Funding acquisition: Myung Jae Baik. Investigation: Dae Jong Oh, Eun Young Kim, Myung Jae Baik. Methodology: Dae Jong Oh, Eun Young Kim, Myung Jae Baik. Project administration: Eun Young Kim, Myung Jae Baik. Resources: Eun Young Kim, Myung Jae Baik. Software: Sae Rom Kim. Supervision: Myung Jae Baik. Validation: Eun Young Kim. Visualization: Dae Jong Oh. Writing_original draft: Dae Jong Oh. Writing-review \& editing: all authors.

\section{ORCID iDs}

\section{Dae Jong Oh}

Eun Young Kim

Myung Jae Baik
Sae Rom Kim https://orcid.org/0000-0002-0195-3490 https://orcid.org/0000-0003-4844-0630 https://orcid.org/0000-0002-2788-6839 https://orcid.org/0000-0001-8989-7405

\section{REFERENCES}

1. Mitchell AJ, Chan M, Bhatti H, Halton M, Grassi L, Johansen C, et al. Prevalence of depression, anxiety, and adjustment disorder in oncological, haematological, and palliative-care settings: a meta-analysis of 94 interview-based studies. Lancet Oncol 2011;12:160-174.

2. Popkin MK, Callies AL, Colon EA, Stiebel V. Adjustment disorders in medically ill inpatients referred for consultation in a university hospital. Psychosomatics 1990;31:410-414.

3. Reed GM, Roberts MC, Keeley J, Hooppell C, Matsumoto C, Sharan P, et al. Mental health professionals' natural taxonomies of mental disorders: implications for the clinical utility of the ICD-11 and the DSM-5. J Clin Psychol 2013;69:1191-1212.

4. Silverstone PH. Prevalence of psychiatric disorders in medical inpatients. J Nerv Ment Dis 1996;184:43-51.

5. Casey PR, Dunn G, Kelly BD, Birkbeck G, Dalgard OS, Lehtinen V, et al. Factors associated with suicidal ideation in the general population: five-centre analysis from the ODIN study. Br J Psychiatry 2006;189: 410-415.

6. Kryzhanovskaya L, Canterbury R. Suicidal behavior in patients with adjustment disorders. Crisis 2001;22:125-131.

7. Lonnqvist JK, Henriksson MM, Isometsa ET, Marttunen MJ, Heikkinen ME, Aro HM, et al. Mental disorders and suicide prevention. Psychiatry Clin Neurosci 1995;49(Suppl 1):S111-S116.

8. Taggart C, O'Grady J, Stevenson M, Hand E, Mc Clelland R, Kelly C. Accuracy of diagnosis at routine psychiatric assessment in patients presenting to an accident and emergency department. Gen Hosp Psychiatry 2006;28:330-335.

9. Ministry of National Defense. The Epidemiological Survey of Psychiatric Illnesses in Military Service. Seoul: Ministry of National Defense; 2007.

10. Maercker A, Forstmeier S, Pielmaier L, Spangenberg L, Brahler E, Glaesmer H. Adjustment disorders: prevalence in a representative nationwide survey in Germany. Soc Psychiatry Psychiatr Epidemiol 2012; 47:1745-1752.

11. Strain JJ, Friedman MJ. Considering adjustment disorders as stress response syndromes for DSM-5. Depress Anxiety 2011;28:818-823.

12. Bronisch T. Adjustment reactions: a long-term prospective and retrospective follow-up of former patients in a crisis intervention ward. Acta Psychiatr Scand 1991;84:86-93.
13. Despland JN, Monod L, Ferrero F. Clinical relevance of adjustment disorder in DSM-III-4 and DSM-IV. Compr Psychiatry 1995;36:454460.

14. Jones R, Yates WR, Zhou MH. Readmission rates for adjustment disorders: comparison with other mood disorders. J Affect Disord 2002; 71:199-203.

15. Looney JG, Gunderson EK. Transient situational disturbances: course and outcome. Am J Psychiatry 1978;135:660-663.

16. Snyder S, Strain JJ, Wolf D. Differentiating major depression from adjustment disorder with depressed mood in the medical setting. Gen Hosp Psychiatry 1990;12:159-165.

17. Barnow S, Linden M, Lucht M, Freyberger HJ. The importance of psychosocial factors, gender, and severity of depression in distinguishing between adjustment and depressive disorders. J Affect Disord 2002; 72:71-78.

18. Casey P, Maracy M, Kelly BD, Lehtinen V, Ayuso-Mateos JL, Dalgard OS, et al. Can adjustment disorder and depressive episode be distinguished? Results from ODIN. J Affect Disord 2006;92:291-297.

19. Fernandez A, Mendive JM, Salvador-Carulla L, Rubio-Valera M, Luciano JV, Pinto-Meza A, et al. Adjustment disorders in primary care: prevalence, recognition and use of services. Br J Psychiatry 2012;201: 137-142.

20. Banki CM, Arato M, Papp Z, Kurcz M. Biochemical markers in suicidal patients. Investigations with cerebrospinal fluid amine metabolites and neuroendocrine tests. J Affect Disord 1984;6:341-350.

21. Lindqvist D, Traskman-Bendz L, Vang F. Suicidal intent and the HPAaxis characteristics of suicide attempters with major depressive disorder and adjustment disorders. Arch Suicide Res 2008;12:197-207.

22. Ader R, Cohen N, Felten D. Psychoneuroimmunology: interactions between the nervous system and the immune system. Lancet 1995; 345:99-103.

23. Oh DJ, Lee DH, Kim EY, Kim WJ, Baik MJ. Altered autonomic reactivity in Korean military soldiers with adjustment disorder. Psychiatry Res 2018;261:428-435.

24. Marques AH, Silverman MN, Sternberg EM. Evaluation of stress systems by applying noninvasive methodologies: measurements of neuroimmune biomarkers in the sweat, heart rate variability and salivary cortisol. Neuroimmunomodulation 2010;17:205-208.

25. Yeragani VK, Pesce V, Jayaraman A, Roose S. Major depression with ischemic heart disease: effects of paroxetine and nortriptyline on longterm heart rate variability measures. Biol Psychiatry 2002;52:418-429.

26. Task Force of the European Society of Cardiology and the North American Society of Pacing and Electrophysiology. Heart rate variability: standards of measurement, physiological interpretation and clinical use. Circulation 1996;93:1043-1065.

27. Cho MJ, Kim KH. Use of the Center for Epidemiologic Studies Depression (CES-D) Scale in Korea. J Nerv Ment Dis 1998;186:304-310.

28. Lee HK, Lee EH, Hwang ST, Hong SH, Kim JH. Psychometric properties of the Beck Anxiety Inventory in the community-dwelling sample of Korean adults. Korean J Clin Psychol 2016;35:822-830.

29. Lee J, Shin C, Ko YH, Lim J, Joe SH, Kim S, et al. The reliability and validity studies of the Korean version of the Perceived Stress Scale. Korean J Psychosom Med 2012;20:127-134.

30. Lee H, Kwon JH. Validation for the Beck Scale for Suicide Ideation with Korean university students. Kor J Clin Psychol 2009;28:1155-1172.

31. Laborde S, Mosley E, Thayer JF. Heart rate variability and cardiac vagal tone in psychophysiological research-recommendations for experiment planning, data analysis, and data reporting. Front Psychol 2017; 8:213.

32. Visnovcova Z, Mestanik M, Javorka M, Mokra D, Gala M, Jurko A, et al. Complexity and time asymmetry of heart rate variability are altered in acute mental stress. Physiol Meas 2014;35:1319-1334.

33. Schiweck C, Piette D, Berckmans D, Claes S, Vrieze E. Heart rate and high frequency heart rate variability during stress as biomarker for clinical depression. A systematic review. Psychol Med 2019;49:200-211. 
34. Lackner HK, Papousek I, Batzel JJ, Roessler A, Scharfetter H, Hinghofer-Szalkay $\mathrm{H}$. Phase synchronization of hemodynamic variables and respiration during mental challenge. Int J Psychophysiol 2011;79:401409.

35. Papousek I, Nauschnegg K, Paechter M, Lackner HK, Goswami N, Schulter G. Trait and state positive affect and cardiovascular recovery from experimental academic stress. Biol Psychol 2010;83:108-115.

36. Hjortskov N, Rissen D, Blangsted AK, Fallentin N, Lundberg U, Sogaard $\mathrm{K}$. The effect of mental stress on heart rate variability and blood pressure during computer work. Eur J Appl Physiol 2004;92:84-89.

37. Taelman J, Vandeput S, Vlemincx E, Spaepen A, Van Huffel S. Instantaneous changes in heart rate regulation due to mental load in simulated office work. Eur J Appl Physiol 2011;111:1497-1505.

38. Reyes del Paso GA, Langewitz W, Mulder LJ, van Roon A, Duschek S. The utility of low frequency heart rate variability as an index of sympathetic cardiac tone: a review with emphasis on a reanalysis of previous studies. Psychophysiology 2013;50:477-487.

39. Shaffer F, McCraty R, Zerr CL. A healthy heart is not a metronome: an integrative review of the heart's anatomy and heart rate variability. Front Psychol 2014;5:1040.

40. Shaffer F, Ginsberg JP. An overview of heart rate variability metrics and norms. Front Public Health 2017;5:258.

41. Liang CS, Lee JF, Chen CC, Chang YC. Reactive heart rate variability in male patients with first-episode major depressive disorder. Prog Neuropsychopharmacol Biol Psychiatry 2015;56:52-57.

42. Kop WJ, Stein PK, Tracy RP, Barzilay JI, Schulz R, Gottdiener JS. Autonomic nervous system dysfunction and inflammation contribute to the increased cardiovascular mortality risk associated with depression. Psychosom Med 2010;72:626-635.

43. Lampert R, Bremner JD, Su S, Miller A, Lee F, Cheema F, et al. Decreased heart rate variability is associated with higher levels of inflammation in middle-aged men. Am Heart J 2008;156:759 e1-e7.

44. Kemp AH, Quintana DS, Gray MA, Felmingham KL, Brown K, Gatt JM. Impact of depression and antidepressant treatment on heart rate variability: a review and meta-analysis. Biol Psychiatry 2010;67:10671074.

45. Licht CM, de Geus EJ, van Dyck R, Penninx BW. Longitudinal evidence for unfavorable effects of antidepressants on heart rate variability. Biol Psychiatry 2010;68:861-868.

46. Licht CM, Penninx BW, de Geus EJ. Effects of antidepressants, but not psychopathology, on cardiac sympathetic control: a longitudinal study. Neuropsychopharmacology 2012;37:2487-2495.

47. Seeman TE, Singer BH, Rowe JW, Horwitz RI, McEwen BS. Price of adaptation--allostatic load and its health consequences. MacArthur studies of successful aging. Arch Intern Med 1997;157:2259-2268. 
Supplementary Table 1. Comparison of heart rate variability parameters between adjustment disorder group and major depressive disorder group*t

\begin{tabular}{|c|c|c|c|}
\hline \multirow{2}{*}{ Group } & Resting phase & Stress phase & Recovery phase \\
\hline & Mean (SD) & Mean (SD) & Mean (SD) \\
\hline \multicolumn{4}{|c|}{ Mean HR (beats/minute) } \\
\hline $\mathrm{AD}$ & $75.32(13.44)$ & $79.36(12.93)$ & $76.21(12.38)$ \\
\hline MDD & $76.67(13.09)$ & $80.63(12.74)$ & $76.27(12.19)$ \\
\hline $\mathrm{t}$ & -0.52 & -0.51 & -0.02 \\
\hline $\mathrm{p}$-value & 0.601 & 0.611 & 0.981 \\
\hline \multicolumn{4}{|l|}{$\mathrm{HF}\left(\mathrm{ms}^{2}\right)$} \\
\hline $\mathrm{AD}$ & $4.14(1.28)$ & $4.50(1.08)$ & $4.20(1.30)$ \\
\hline MDD & $3.76(1.40)$ & $4.24(0.89)$ & $3.74(1.34)$ \\
\hline $\mathrm{t}$ & 1.46 & 1.32 & 1.81 \\
\hline $\mathrm{p}$-value & 0.146 & 0.189 & 0.073 \\
\hline \multicolumn{4}{|l|}{$\mathrm{LF}\left(\mathrm{ms}^{2}\right)$} \\
\hline $\mathrm{AD}$ & $4.76(0.96)$ & $5.13(0.87)$ & $4.97(0.89)$ \\
\hline MDD & $4.27(1.12)$ & $4.76(0.78)$ & $4.52(1.13)$ \\
\hline $\mathrm{t}$ & 2.45 & 2.33 & 2.36 \\
\hline $\mathrm{p}$-value & 0.016 & 0.022 & 0.020 \\
\hline \multicolumn{4}{|l|}{$\operatorname{VLF}\left(\mathrm{ms}^{2}\right)$} \\
\hline $\mathrm{AD}$ & $4.47(0.85)$ & $4.25(0.84)$ & $4.66(0.92)$ \\
\hline MDD & $3.97(0.93)$ & $3.94(0.80)$ & $4.33(0.97)$ \\
\hline $\mathrm{t}$ & 2.91 & 1.98 & 1.77 \\
\hline p-value & 0.004 & 0.050 & 0.080 \\
\hline \multicolumn{4}{|l|}{$\mathrm{TP}\left(\mathrm{ms}^{2}\right)$} \\
\hline $\mathrm{AD}$ & $5.68(0.91)$ & $5.86(0.85)$ & $5.87(0.92)$ \\
\hline MDD & $5.22(1.07)$ & $5.51(0.77)$ & $5.42(1.07)$ \\
\hline $\mathrm{t}$ & 2.45 & 2.20 & 2.34 \\
\hline $\mathrm{p}$-value & 0.016 & 0.030 & 0.021 \\
\hline \multicolumn{4}{|l|}{$\mathrm{LF} / \mathrm{HF}$} \\
\hline $\mathrm{AD}$ & $0.62(0.87)$ & $0.77(0.68)$ & $0.77(0.94)$ \\
\hline MDD & $0.51(0.84)$ & $0.60(0.49)$ & $0.78(0.77)$ \\
\hline $\mathrm{t}$ & 0.68 & 1.47 & -0.03 \\
\hline $\mathrm{p}$-value & 0.499 & 0.146 & 0.980 \\
\hline \multicolumn{4}{|c|}{ SDNN (ms) } \\
\hline $\mathrm{AD}$ & $3.90(0.45)$ & $3.95(0.44)$ & $4.00(0.47)$ \\
\hline MDD & $3.69(0.57)$ & $3.80(0.39)$ & $3.78(0.52)$ \\
\hline $\mathrm{t}$ & 2.10 & 1.85 & 2.35 \\
\hline $\mathrm{p}$-value & 0.038 & 0.066 & 0.021 \\
\hline
\end{tabular}

*comparison by the Student's t-test, ${ }^{\dagger}$ all variables except the mean HR were logarithmically transformed due to their skewed distribution. AD: adjustment disorder, MDD: major depressive disorder, HR: heart rate, HF: high frequency band, LF: low frequency band, VLF: very low frequency band, TP: total power, LF/HF: ratio of LF to HF power, SDNN: standard deviation of normal-to-normal interbeat intervals 